\title{
Descriptive and Analytical Analysis of Dengue Reported Cases in a Medium-Sized Municipality of the State of Pernambuco, 2015
}

Tamyres Leite de Aguiar Arcanjo ${ }^{1}$, Andrezza Fabianni Pedrosa dos Santos Lima ${ }^{2}$, Emilly Tainá Batista da Silva ${ }^{3}$, Emivaldo Batista da Silva ${ }^{4 *}$, Joana Bulhões Alvares da Silva Lima ${ }^{5}$, Valéria Bezerra da Silva ${ }^{6}$, Suelane Michelly Ferreira Alves ${ }^{7}$, Cláudio Junyo dos Santos ${ }^{8}$, Simara Lopes Cruz Damazio", Islane Cristina Martins ${ }^{10}$, Antônio Flaudiano Bem Leite ${ }^{11}$, Ana Greice Borba Leite ${ }^{12}$, Anne Mayara do Carmo Matias de Lima ${ }^{13}$, Emanuella Barros de Souza Oliveira Alvares ${ }^{14}$

1,4,5,8 Department of Pharmaceutical Sciences, University Center of Vitória de Santo Antão - UNIVISA, Vitória de Santo Antão

2,6,7 Department of Nutrition, University Center of Vitória de Santo Antão - UNIVISA, Vitoria de Santo Antão

3 Department of Biomedicine, University Center of Vitória de Santo Antão - (UNIVISA) Vitoria de Santo Antão

9 Department of Nursing Federal University of Pernambuco, Vitória de Santo Antão, PE, Brazil.

10.11 Department of Collective Health Federal University of Pernambuco, Vitória de Santo Antão, PE, Brazil.

12 Department of Veterinary Medicine Rural University of Pernambuco, Recife - PE

13 Department of Dentistry, Tiradentes University Center (UNIT-PE) Recife - PE

14 Department of Biology, Center for Biological Sciences, Professor of the Degree Course in Biology, University Center of Vitória de Santo Antão (UNIVISA), Vitória de Santo Antão, Brazil

E-mail adresses: tamyres.202011023@univisa.edu.br (Tamyres leite de Aguiar Arcanjo), andrezzafpslima@hotmail.com (Andrezza Fabianni Pedrosa dos Santos Lima), emilly.taina@hotmail.com (Emilly Tainá Batista da Silva), emivaldobatista4@gmail.com (Emivaldo Batista da Silva), joanafarmacia2018@gmail.com (Joana Bulhões Alvares da Silva Lima), valeriabezerra.s@hotmail.com (Valéria Bezerra da Silva), 1lanealves82@gmail.com (Suelane Michelly Ferreira Alves), claudiojunyodosantos@gmail.com (Claudio junyo dos santos), simara.cruz@ufpe.br (Simara Lopes Cruz), islanemartins@gmail.com (Islane Cristina Martins), afbl@outlook.com.br (Antônio Flaudiano Bem Leite), ag_mv530@hotmail.com (Ana Greice Borba Leite). Anne1996.am@gmail.com (Anne Mayara do Carmo Matias de Lima), emanuella.barros@hotmail.com (Emanuella Barros de Souza Oliveira Alvares)

${ }^{*}$ Corresponding author

\section{To cite this article:}

Arcanjo, T.L.A.; Lima, A.F.P.S.; Silva, E.T.B.; Silva, E.B.; Lima, J.B.A.S.; Silva, V.B.; Alves, S.M.F.; Santos, C.J.; Damazio, S.L.C.; Martins, I.C.; Leite, A.F.B.; Leite, A.G.B.; Lima, A.M.C.M.; Álvares, E.B.S.O. Descriptive and Analytical Analysis of Dengue Reported Cases in a Medium-Sized Municipality of the State of Pernambuco, 2015. International Journal of Sciences. Vol. 3, No. 1, 2022, pp.29-34. ISSN 27635392.

Received: 11 24, 2021; Accepted: 12 26, 2021; Published: 01 15, 2022

\begin{abstract}
Dengue is a serious public health problem, described as acute febrile illness, having a benign or severe course, depending on its presentation. The study aimed to present an analytical descriptive analysis of reported dengue cases in the municipality of Vitória de Santo Antão - PE. A bank was built in the Microsoft Excel spreadsheet, exported to the SPSS program, version 21 , and analyzed. To evaluate the distribution of the personal and clinical profile of the patients, the percentage frequencies were calculated and the frequency distributions were constructed. The prevalence of symptoms presented by the patients was calculated and which factors were associated with the diagnosis of dengue, constructing contingency tables and applying the Chi-square test for independence. Gross Odds Ration and confidence intervals were obtained. The factors that presented significance in the bivariate analysis were included in the multivariate analysis. For the permanence of the factors in the model, the significance level of $5 \%$ was considered. The results were significant in relation to the characterization of the factors of the personal profile of the patients, indicating a higher prevalence of the disease in men (50.1\%), aged 20 to 30 years $(15.9 \%)$ and brown/black color/race $(85.6 \%)$. The majority were not hospitalized $(89.5 \%)$, being confirmed/discarded by epidemiological clinical criterion (92.2\%), had cure of the disease (99. 8\%), had dengue (61.0\%) and three symptoms $(35.9 \%)$.
\end{abstract}


2 Arcanjo, T.L.A.; Lima, A.F.P.S.; Silva, E.T.B.; Silva, E.B.; Lima, J.B.A.S.; Silva, V.B.; Alves, S.M.F.; Santos, C.J.; Damazio, S.L.C.; Martins, I.C.; Leite, A.F.B.; Leite, A.G.B.; Lima, A.M.C.M.; Álvares, E.B.S.O. Descriptive and Analytical Analysis of Dengue Reported Cases in a Medium-Sized Municipality of the State of Pernambuco, $2015 \ldots$

It is important that health professionals correctly fill out compulsory notification forms and that epidemiological weeks are properly fed with valuable information so that actions can be implemented.

Keywords: Descriptive Analysis. Analytical Analysis. Dengue fever. Epidemiology. Health Information Systems

\section{Introduction}

Among the reemerging diseases, according to the World HealthOrganization 1,dengue is a serious public health problem. Described as acute febrile disease pathology, having a benign or severe course, depending on the form presented: dengue without alarm signs, dengue with alarm signs and severe dengue. The year 2015 was considered the most epidemic regarding dengue disease in Brazil, surpassing the epidemiological records consolidated in previous years, 2010 and 2013, which was the period in which notifications presented a categorization pattern.

In reference to the study by Araújo et al. 2 There was a significant increase in dengue virus infection in Brazil during the period from 2000 to 2015 , highlighting incidence and mortality rates. This growth totaled $232.7 \%$ in the case index and $639.0 \%$ in the rate of deaths.

According to data from the epidemiological bulletins of the Ministry of Health, in the last three years, 2014, 2015 and 2016 the four different serotypes continued circulating throughout the country and infecting populations 3 .

Despite increasing efforts and encouragement of practices that can contribute to the eradication of the mosquito, it is noted that its proliferation has still been exponential, demonstrating the need for change in strategies to combatit 1 .

Inreference, the calculations on dengue do not reveal the real situation of the occurrence of the disease due to the underreporting of cases. Symptomatic cases of dengue present a wide change in the spectrum of the disease and several patients do not seek treatment 4 .

Therefore, considering the various studies that demonstrate and affirm the relationship of environmental determinants and climatic factors under the dynamics of endemic smaemias, and knowing the relevance and magnitude of dengue in Brazil and worldwide, it is relevant to develop a study that presents a descriptive and analytical analysis of reported dengue cases in the municipality of Vitória de Santo Antão, PE, 2015.

The present study aims to present an analytical descriptive analysis of about the reported cases of dengue in the municipality of Vitória de Santo Antão, PE, 2015.

\section{Methodology}

\section{Type of study}

A descriptive, epidemiological study of the populationbased spatial type (case-control) of the spatial distribution of dengue cases occurred in the municipality of Vitória de Santo Antão in 2015 was carried out.

\section{Study population}

The study population consisted of the reported cases of dengue in 2015, in the municipality of Vitoria de Santo Antão and consolidated in the Notifiable Diseases Information System SINAN.

\section{Inclusion and exclusion criteria}

The description of the control case respected the categorization offered by the Health Surveillance Guide published in 2014 effective until the beginning of 2016 and SINAN's online dictionary.

Inclusion criteria - The inclusion criteria of the research were defined by all reported cases of dengue in 2015, in the municipality of Vitória de Santo Antão and consolidated in the Notifiable Diseases Information System - SINAN. Being named as: Confirmed cases of dengue by epidemiological clinical investigation or confirmed cases of dengue by laboratory investigation.

Exclusion criteria - The exclusion criteria of the research were defined by all reported cases of dengue in 2015, in the municipality of Vitória de Santo Antão and consolidated in the Notifiable Diseases Information System - SINAN. Being named as: Discarded cases of dengue and inconclusive cases.

\section{The area of study}

The municipality of Vitória de Santo Antão has a territorial area of approximately $335,942 \mathrm{~km}^{2}$, with $5.717 \mathrm{~km}^{2}$ in urban perimeter, with an estimated population of 136,706 inhabitants and a population density of 348.80 inhabitants $/ \mathrm{km}^{2}$, according to the population census of 2010 (IBGE, 2010).

\section{Statistical plan \\ Database construction}

For data analysis, a database was built in the Microsoft Excel spreadsheet, which was exported to the SPSS program, version 21 , where the analysis was performed. To evaluate the distribution of the personal and clinical profile of the patients, the percentage frequencies were calculated and the respective frequency distributions were constructed. Furthermore, the prevalence of symptoms presented by the patients in the study was calculated. To determine which factors are associated with the diagnosis of dengue, contingency tables were constructed and the Chi-square test for independence was applied. Crude Odds Ration and their respective confidence intervals were obtained. The factors that presented significance in the bivariate analysis were included in the Multivariate analysis. All conclusions were drawn considering the significance level of $5 \%$.

The variables that presented statistical significance up to $20 \%$ in the bivariate analysis were included in the adjustment of the multivariate logistic model for the diagnosis of dengue. For the permanence of the factors in the model, the significance level of 5\% was considered. Furthermore, the confidence intervals for the prevalence ratio and the Wald test 
were calculated in the comparison of risks between the levels of the factors evaluated.

\section{Results and Discussion}

Table 1 shows the characterization of the factors of the personal profile of the patients evaluated. It was verified that the majority are male $(50.1 \%)$, are aged 20 to 30 years $(15.9 \%)$, are not pregnant $(97.9 \%)$ and are brown/black $(85.6 \%)$. It is observed that the proportion comparison test was significant in all factors evaluated, except for gender ( $\mathrm{p}$ value $=0.922$ ), indicating that the number of male patients is similar to the number of female patients. Furthermore, the confidence intervals were calculated for the estimated prevalence.

Table 2 shows the distribution of the clinical situation of the patients evaluated. It was verified that the majority did not go through hospitalization (89.5\%), was confirmed/discarded by the epidemiological clinical criterion $(92.2 \%)$, had cure of the disease $(99.8 \%)$, had dengue $(61.0 \%)$ and 3 symptoms $(35.9 \%)$. The distribution comparison test was significant in all factors evaluated. Indicating that the profile described is relevantly the most frequent in the group of patients evaluated.

Table 3 shows the distribution of the comorbidities evaluated. The most prevalent symptoms were: Fever (84.0\%), Exanthema (55.5\%) and Myalgia (53.5\%). The distribution comparison test was significant in all symptoms evaluated ( $p$-value $<0.05)$, except for headache ( $p$-value $=$ 0.588 ) indicating that the prevalence of patients who presented this symptom is similar to those who did not.

\section{Bivariate Analysis}

Table 4 shows the distribution of dengue diagnosis according to the personal characteristics of patients. There is a higher prevalence of dengue in female patients $(63.5 \%)$, aged between 40 and less than 50 years $(72.5 \%)$, who are women of childbearing age, but have no child $(68.5 \%)$ and white/yellow/indigenous (72.3\%). Furthermore, we have the analysis of the crude Odds Ratio for each category of variables comparing with the reference category (lower prevalence of dengue positivity).

Table 5 shows the distribution of dengue diagnosis according to the clinical situation of patients. There was a higher prevalence of dengue in hospitalized patients $(82.1 \%)$, clinically evaluated (61.6\%), who obtained cure $(61.1 \%)$ and who had 6 or more symptoms $(80.7 \%)$. Inda, we have the analysis of the odds ration (odds ratio) gross for each category of variables comparing with the reference category (lower prevalence of dengue positivity).

\section{Multivariate Analysis}

Table 6 shows the adjustment of the Logistic model for the diagnosis of dengue. It was verified that the variables evaluated in the study were those that remained jointly significant for the diagnosis of Dengue were: Gender, age group, race, occurrence of hospitalization, confirmation/disposal criteria and number of symptoms There was a significant increase in the chance of positive diagnosis of dengue when the patient is female $(\mathrm{OR}=1.241)$, aged 40 to 50 years $(\mathrm{OR}=1.917)$, is white/yellow/indigenous $(\mathrm{OR}=1.771)$, is hospitalized $(\mathrm{OR}$ $=2.327)$, receives epidemiological clinical evaluation $(\mathrm{OR}=$ 1.869 ) and presents a higher number of symptoms (OR directly proportional to the number of symptoms being $\mathrm{OR}=$ 3.823 to the group with 6 or more symptoms).

The ROC curve graph shows an area of 0.663 for the model suggested in Table 6 , indicating a significant discriminatory power.

\section{Discussion}

The findings of the present study demonstrated significant results in relation to the characterization of the factors of the personal profile of the patients evaluated in the municipality of Vitória de Santo Antão. Indicating that the prevalence of the disease occurs in greater quantity, respectively: in males $(50.1 \%)$, aged 20 to 30 years $(15.9 \%)$, is not pregnant $(97.9 \%)$ and is brown/black $(85.6 \%)$. However, a study by Oliveira et al. 5 identifies a greater involvement in females and in the age group between 15 and 19 years, followed by 20 and 34 years. This same study found the prevalence of dengue notifications, approximately $55.91 \%$ of cases, in females $(\mathrm{n}=2,036)$.

Flauzino et al. 6 state that the female sex is more affected by the disease, due to the prevalence of women in the home environment, and because they are the ones who most seek the health service, which was also observed in the study. A higher prevalence was obtained in the age group of 20 to 30 years of individuals reported with dengue, which corroborates with other studies, according to which the most affected individuals belong to the working class.

The confirmed cases of dengue, according to gender, presented the following results: in all years there was a predominance of dengue cases in females; in 2008, 63.93\%; $2009,70,27 \%$; 2010, 66,67\%; $2011,60 \%$ and $2012,70.69 \%$. The most affected age group was 35 to 49 years in 2008; 20 to 34 years in 2009 and $2010 ; 1$ to 4 years in 2011 and 15 to 19 years in 20127. In general, the age group with the highest number of notifications is between 20 and 59 years 8 .

Severe cases and deaths in particular were not investigated, but the age group most affected by dengue in the period was between 20 and 59 years, which corresponds to the economically active population, who work or study during the day. Women had a small difference in the distribution of cases and were more affected than men8.

Regarding the distribution of the clinical situation of the patients evaluated, it was found that most individuals did not go through hospitalization (89.5\%), being confirmed/discarded by epidemiological clinical criterion (92.2\%), had cure of the disease $(99.8 \%)$, had dengue $(61.0 \%)$ and 3 symptoms (35.9\%). In the study conducted by Carvalho, Magalhães and Medronho10, the results found suggest that barriers to access to health services interfere in the early diagnosis of dengue, leading to the greater possible 
4 Arcanjo, T.L.A.; Lima, A.F.P.S.; Silva, E.T.B.; Silva, E.B.; Lima, J.B.A.S.; Silva, V.B.; Alves, S.M.F.; Santos, C.J.; Damazio, S.L.C.; Martins, I.C.; Leite, A.F.B.; Leite, A.G.B.; Lima, A.M.C.M.; Álvares, E.B.S.O. Descriptive and Analytical Analysis of Dengue Reported Cases in a Medium-Sized Municipality of the State of Pernambuco, 2015 ...

cases of severe dengue, since the late diagnosis of the disease may imply the non-identification of the alarm signs of the disease. It is noteworthy that the improvement of access to health services is related to the principle of universality provided for in the Unified Health System.

The spread and flow of the various serotypes of dengue virus over the years also has a significant influence on epidemics, as well as the increase in cases diagnosed by the most severe form of the disease. These factors demonstrate the importance of introducing preventive measures in order to reduce dengue rates 2 .

The study shows that higher numbers of cases are confirmed in individuals from the urban area of the municipality of Vitória de Santo Antão.

It is verified in relation to the distribution of the diagnosis of dengue according to the personal characteristics of patients that the highest prevalence of dengue is found in female patients $(63.5 \%)$, aged between 40 and less than 50 years $(72.5 \%)$, who are women of childbearing age, but have no child (68.5\%) and white/yellow/indigenous (72.3\%). The female gender is more affected by the disease, due to the prevalence of women in the home environment, and because they are the ones who most seek the health service, which was also observed in the study. A higher prevalence was obtained in the age group of 20 to 30 years of individuals reported with dengue, which corroborates with other studies, according to which the most affected individuals belong to the working class6.

It is observed that, in 2015, there was an increase in the number of dengue cases, characterizing an epidemic transmission in the municipality. According to Vasconcelos11, although year after year there has been an increase in the number of dengue cases reported, during the occurrence of epidemics it is well known that the number of reported cases does not represent the total number of cases that occurred, indicate that only between $5 \%$ and $10 \%$ of the infections that occurred are reported.

\section{Conclusion}

It is noteworthy the difficulty in finding statistical information of dengue cases in a centralized and standardized way, which facilitated data studies and would enable the proposal of new visions of analysis.

Therefore, it is necessary to emphasize the importance of correct filling out compulsory notification forms by health professionals, avoiding that epidemiological weeks are not properly fed with valuable information so that actions can be implemented and that seasonality is an important reference in the preparation of strategies to combat the vector and organize the care network in order to better lead health problems.

\section{Ethical Aspects}

This research was approved by the Research Ethics Committee involving human beings of the Center for Health

\section{Sciences of UFPE.}

Data were collected after approval of this body. The technique applied in this research was to search for secondary data in SINAN.

The research sought to meet the recommendations of Resolution No. 466/12 of the National Health Council/Ministry of Health - CNS/MS, which provides for the standards applicable to research in Human and Social Sciences whose methodological procedures involve the use of data directly obtained from participants or identifiable information or that may entail greater risks than those existing in everyday life, in the defined form found in the above-mentioned Resolution.

\section{Acknowledgments}

To the Department of Health Surveillance of the Municipality of Vitória de Santo Antão, PE.

\section{References}

[1] World Health Organization. Dengue and severe dengue [Internet]. Disponível em: Disponível em: http://www.who.int/mediacentre/factsheets/fs117/en/ 2016.

[2] Araújo VEM, et al. Aumento da carga de dengue no Brasil e unidades federadas, 2000 e 2015: análise do Global Burden of Disease Study 2015. Rev Bras Epidemiol. 2017;20(1):205-216.

[3] Brasil. Ministério da Saúde. Secretaria de Vigilância em Saúde. Monitoramento dos casos de dengue, febre de chikungunya e febre pelo vírus Zika até a Semana Epidemiológica 3. Bol Epidemiol. 2015.

[4] Bhatt S, Gething PW, Brady OJ, Messina JP, Farlow AW, Moyes CL, et al. The global distribution and burden of dengue. Nature 2013;496(7446):504-7.

[5] Oliveira MACA, Coelho FAC, Freitas RB, Tavares AP, Silva INPN, Pinto SS. et al. Perfil das notificações de dengue e sazonalidade no município de UBÁ-MG, 2015 A 2016. Rev. Ciênt. Fagoc. 2017;2(2).

[6] Flauzino RF, Souza-Santos R, Barcellos C, Gracie R, Magalhães MAFM, Oliveira RM. Heterogeneidade espacial da dengue em estudos locais, Niterói, RJ. Rev. Saúde Pública. 2009;43(6):1035-43.

[7] Silva BGM, Andrade AMSS. Avaliação do perfil epidemiológico da dengue no município de Paripiranga, Bahia. Scientia Plena. 2014;10(9).

[8] Ferreira AC, Chiaravalloti Neto F, Mondini A. Dengue em Araraquara, SP: epidemiologia, clima e infestação por Aedes aegypti. Rev. Saude Publica. 2018; 52:18.

[9] Carvalho S, Magalhães MAFM, Medronho RA. Análise da distribuição espacial de casos da dengue no município do Rio de Janeiro, 2011 e 2012. Rev. Saúde Pública. 2017; $51: 1$. 
Table 1. Characterization of the patients evaluated.

\begin{tabular}{|c|c|c|c|c|}
\hline Factor evaluated & $\mathbf{N}$ & $\%$ & $\begin{array}{c}\text { CI } \\
(95 \%) \\
\end{array}$ & p-value ${ }^{1}$ \\
\hline Sex & & & & \multirow[b]{2}{*}{0,922} \\
\hline Male & 822 & 50,1 & $\begin{array}{c}47,7- \\
52,5 \\
47,5- \\
52,3 \\
\end{array}$ & \\
\hline \multicolumn{5}{|l|}{ Age } \\
\hline Less than 1 year & 97 & 5,9 & $4,8-7,1$ & \\
\hline 1 to less than 5 years & 213 & 12,9 & $\begin{array}{c}11,4- \\
14,6\end{array}$ & \\
\hline 5 to less than 10 years & 216 & 13,1 & $\begin{array}{c}11,6- \\
14,8\end{array}$ & \\
\hline 10 to less than 20 years & 229 & 13,9 & $\begin{array}{c}12,3- \\
15,6\end{array}$ & \\
\hline 20 to under 30 years & 262 & 15,9 & $\begin{array}{c}14,2- \\
17,7\end{array}$ & $<0,001$ \\
\hline 30 to less than 40 years & 191 & 11,6 & $\begin{array}{c}10,1- \\
13,2\end{array}$ & \\
\hline 40 to less than 50 years & 171 & 10,4 & $\begin{array}{l}8,9- \\
11,9\end{array}$ & \\
\hline 50 to under 60 years & 114 & 6,9 & $5,8-8,2$ & \\
\hline 60 years or more & 155 & 9,4 & $\begin{array}{l}8,1- \\
10,9\end{array}$ & \\
\hline
\end{tabular}

\begin{tabular}{lcccc}
\hline CS_gestante & 35 & 2,1 & $1,5-2,9$ & \\
Pregnant & & & $19,7-$ & \\
& 356 & 21,6 & 23,6 & \\
You don't have a child & & & $24,1-$ & $<0,001$ \\
& 431 & 26,2 & 28,3 & \\
Non-fertile & & & $47,7-$ & \\
& 826 & 50,1 & 52,5 & \\
Does not apply & & & &
\end{tabular}

\section{Race}

\begin{tabular}{lcccc} 
White/yellow/indigenous & 238 & 14,4 & $12,8-$ & \\
& & & 16,2 & $<0,001$ \\
Brown/black (exposed) & 1410 & 85,6 & $83,8-$ & \\
& & & 87,2 & \\
\hline
\end{tabular}

${ }^{1} \mathrm{p}$-value of the Chi-square test for proportion comparison. IC $=$ confidence interval. Source: Prepared by the author.

Table 2. Distribution of the clinical situation of the patients evaluated.

\begin{tabular}{|c|c|c|c|c|}
\hline Factor evaluated & $\mathbf{N}$ & $\%$ & CI $(95 \%)$ & p-value ${ }^{1}$ \\
\hline \multicolumn{5}{|l|}{ Hospitalization occurred } \\
\hline Yes & 173 & 10,5 & $9,1-12,1$ & \multirow{2}{*}{$<0,001$} \\
\hline No & 1475 & 89,5 & $87,9-90,9$ & \\
\hline
\end{tabular}

Confirmation Criterion/

Disposal

\begin{tabular}{lcccc} 
Laboratory & 128 & 7,8 & $6,6-9,2$ & $<0,001$ \\
Epidemiological Clinical & 1520 & 92,2 & $7,0-10,1$ & \\
\hline $\begin{array}{l}\text { Evolution of the Case } \\
\text { Healing }\end{array}$ & 1645 & 99,8 & $99,5-99,9$ & $<0,001$ \\
Death Dpelo injury & 3 & 0,2 & $0,1-0,5$ & \\
\hline $\begin{array}{l}\text { Dengue fever } \\
\text { Yes }\end{array}$ & 1005 & 61,0 & $58,6-63,3$ & $<0,001$
\end{tabular}

\begin{tabular}{lcccc} 
No & 643 & 39,0 & $36,7-41,4$ & \\
\hline $\begin{array}{l}\text { Number of symptoms } \\
\text { Up to } 1 \text { symptom }\end{array}$ & 85 & 5,2 & $4,2-6,3$ & \\
2 symptoms & 316 & 19,2 & $17,4-21,1$ & \\
3 symptoms & 591 & 35,9 & $33,6-38,2$ & $<0,001$ \\
4 symptoms & 400 & 24,3 & $22,3-26,4$ & \\
5 symptoms & 173 & 10,5 & $9,1-12,1$ & \\
6 or more symptoms & 83 & 4,9 & $4,1-6,2$ & \\
\hline
\end{tabular}

${ }^{1} \mathrm{p}$-value of the Chi-square test for proportion comparison. IC $=$ confidence interval. Source: Prepared by the author.

Table 3. Distribution of comorbidities evaluated.

\begin{tabular}{|c|c|c|c|c|}
\hline \multirow[b]{2}{*}{$\begin{array}{c}\text { Factor } \\
\text { evaluated }\end{array}$} & \multicolumn{2}{|c|}{ It has comorbidity } & \multirow{2}{*}{$\begin{array}{c}\text { CI for } \\
\text { occurrence } \\
\text { of the event } \\
(95 \%) \\
\end{array}$} & \multirow[b]{2}{*}{$\begin{array}{c}\text { p- } \\
\text { value }^{1}\end{array}$} \\
\hline & Yes & No & & \\
\hline Fever & $1385(84,0 \%)$ & $263(16,0 \%)$ & $82,2-85,7$ & $<0,001$ \\
\hline Rash & $914(55,5 \%)$ & $734(44,5 \%)$ & $53,0-57,8$ & $<0,001$ \\
\hline Myalgia & $882(53,5 \%)$ & $766(46,5 \%)$ & $51,1-55,9$ & 0,004 \\
\hline Headache & $835(50,7 \%)$ & $813(49,3 \%)$ & $48,2-53,1$ & 0,588 \\
\hline Arthralgia & $693(42,1 \%)$ & $955(57,9 \%)$ & $39,7-44,4$ & $<0,001$ \\
\hline Dor_retroorbital & $288(17,5 \%)$ & $1360(82,5 \%)$ & $15,7-19,4$ & $<0,001$ \\
\hline Vomit & $214(13,0 \%)$ & $1434(87,0 \%)$ & $11,4-14,7$ & $<0,001$ \\
\hline Petequia_n & $106(6,4 \%)$ & $1542(93,6 \%)$ & $5,4-7,7$ & $<0,001$ \\
\hline Nausea & $90(5,5 \%)$ & $1558(94,5 \%)$ & $4,4-6,7$ & $<0,001$ \\
\hline Leukopenia & $44(2,7 \%)$ & $1604(97,3 \%)$ & $2,0-3,6$ & $<0,001$ \\
\hline Dor_costas & $9(0,5 \%)$ & $1639(99,5 \%)$ & $0,3-1,0$ & $<0,001$ \\
\hline Conjuntvit & $8(0,5 \%)$ & $1640(99,5 \%)$ & $0,2-1,0$ & $<0,001$ \\
\hline Arthritis & $1(0,1 \%)$ & $1647(99,9 \%)$ & $0,0-0,3$ & $<0,001$ \\
\hline Sin_gravid & $0(0,0 \%)$ & $1648(100,0 \%)$ & $0,0-0,2$ & $<0,001$ \\
\hline
\end{tabular}

Table 4. Distribution of dengue diagnosis according to the personal characteristics of the patients evaluated

\begin{tabular}{|c|c|c|c|c|c|}
\hline \multirow[b]{2}{*}{ Factor evaluated } & \multicolumn{2}{|c|}{ Dengue fever } & \multirow[b]{2}{*}{ OR } & \multirow{2}{*}{$\begin{array}{c}\text { IC95 } \\
\% \\
\text { (OR) } \\
\end{array}$} & \multirow{2}{*}{$\begin{array}{c}\text { p- } \\
\text { value }^{1}\end{array}$} \\
\hline & Yes & No & & & \\
\hline \multicolumn{6}{|l|}{ Sex } \\
\hline Male & $\begin{array}{c}483(58,5 \% \\
)\end{array}$ & $\begin{array}{c}343(41,5 \% \\
)\end{array}$ & $\begin{array}{c}1,0 \\
0\end{array}$ & - & \\
\hline Female & $\begin{array}{c}522(63,5 \% \\
)\end{array}$ & $\begin{array}{c}300(36,5 \% \\
)\end{array}$ & $\begin{array}{c}1,2 \\
4 \\
\end{array}$ & $\begin{array}{c}1,01- \\
1,51\end{array}$ & 0,036 \\
\hline \multicolumn{6}{|l|}{ Age } \\
\hline Less than 1 year & $48(49,5 \%)$ & $49(50,5 \%)$ & $\begin{array}{c}1,1 \\
4\end{array}$ & $\begin{array}{c}0,68- \\
1,89\end{array}$ & 0,601 \\
\hline 1 to less than 5 years & $\begin{array}{c}122(57,3 \% \\
)\end{array}$ & $91(42,7 \%)$ & $\begin{array}{c}1,5 \\
6\end{array}$ & $\begin{array}{c}1,04- \\
2,32\end{array}$ & 0,023 \\
\hline 5 to less than 10 years & $\begin{array}{c}100(46,3 \% \\
)\end{array}$ & $\begin{array}{c}116(53,7 \% \\
)\end{array}$ & $\begin{array}{c}1,0 \\
0\end{array}$ & - & - \\
\hline 10 to less than 20 years & $\begin{array}{c}123(53,7 \% \\
)\end{array}$ & $\begin{array}{c}106(46,3 \% \\
)\end{array}$ & $\begin{array}{c}1,3 \\
5\end{array}$ & $\begin{array}{c}0,91- \\
1,99\end{array}$ & 0,118 \\
\hline 20 to under 30 years & $\begin{array}{c}172(65,6 \% \\
)\end{array}$ & $90(34,4 \%)$ & $\begin{array}{c}2,2 \\
2\end{array}$ & $\begin{array}{c}1,51- \\
3,26\end{array}$ & $\begin{array}{c}<0,00 \\
1\end{array}$ \\
\hline 30 to less than 40 years & $\begin{array}{c}129(67,5 \% \\
)\end{array}$ & $62(32,5 \%)$ & $\begin{array}{c}2,4 \\
1\end{array}$ & $\begin{array}{l}1,58- \\
3,69\end{array}$ & $\begin{array}{c}<0,00 \\
1\end{array}$ \\
\hline 40 to less than 50 years & $124(72,5 \%$ & $47(27,5 \%)$ & 3,0 & $1,95-$ & $<0,00$ \\
\hline
\end{tabular}


6 Arcanjo, T.L.A.; Lima, A.F.P.S.; Silva, E.T.B.; Silva, E.B.; Lima, J.B.A.S.; Silva, V.B.; Alves, S.M.F.; Santos, C.J.; Damazio, S.L.C.;

Martins, I.C.; Leite, A.F.B.; Leite, A.G.B.; Lima, A.M.C.M.; Álvares, E.B.S.O. Descriptive and Analytical Analysis of Dengue Reported Cases in a Medium-Sized Municipality of the State of Pernambuco, 2015 ...

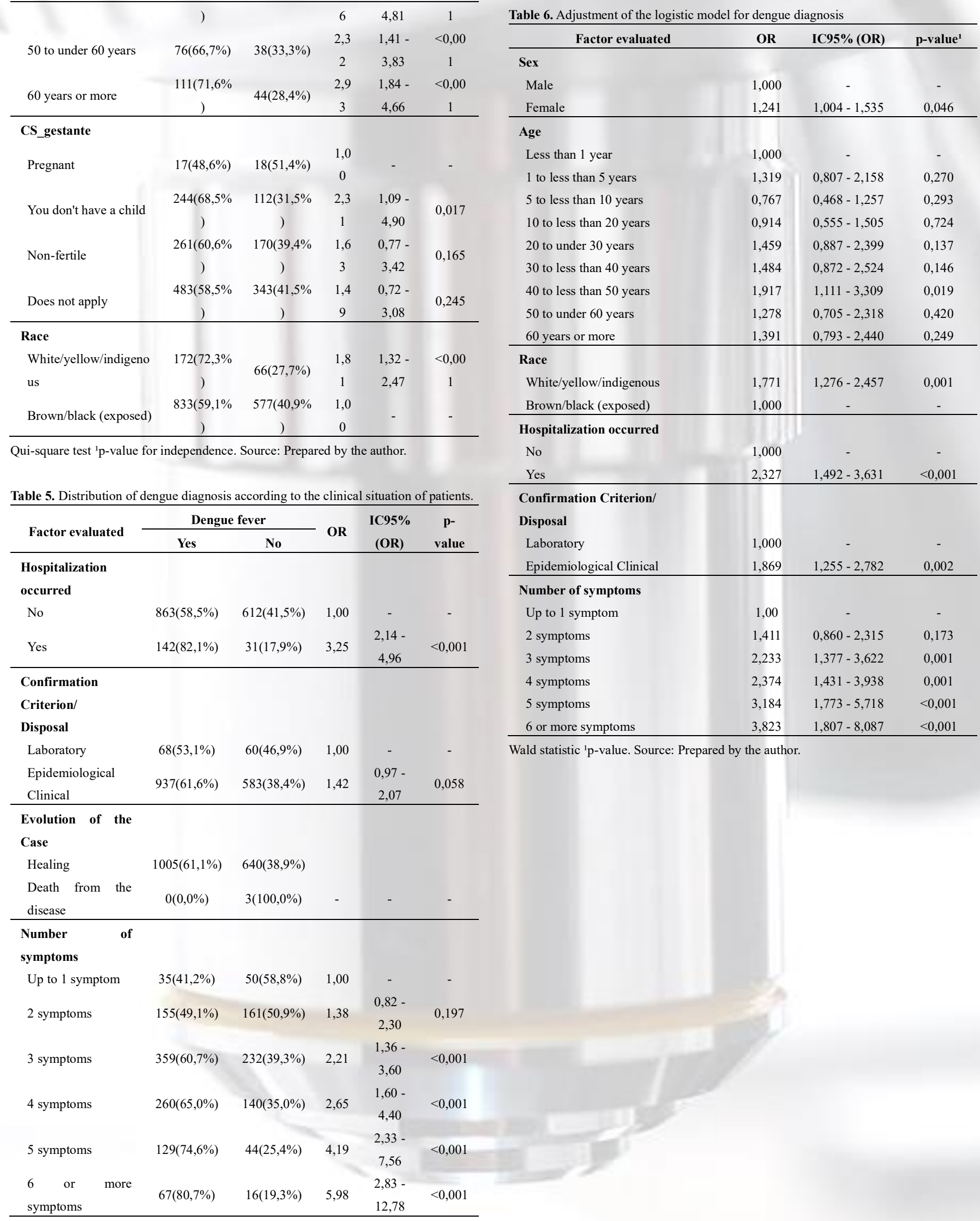

Qui-square test ${ }^{1} \mathrm{p}$-value for independence. Source: Prepared by the author. 